\title{
Estado vacinal de adolescentes de uma unidade básica de saúde
}

\author{
Vaccination status of adolescents from a basic health unit
}

Condición de vacunación de los adolescentes de una unidad básica de salud

\begin{abstract}
Antônio Tiago da Silva Souza ${ }^{1 *}$, Laís Resende de Sousa Amaral ${ }^{2}$, Marianne dos Santos Pereira ${ }^{3}$, Valderlene dos Santos Freire ${ }^{3}$, Alysson Santos Alves ${ }^{1}$, Arthur Phillipe Machado Araújo4, Carlos Eduardo Bezerra Pontes ${ }^{1}$, Francisco Lukas Rodrigues Martins ${ }^{1}$, Francisco Ricardo Nascimento Freitas ${ }^{1}$, Raimundo Graças Almeida Lima Neto'.
\end{abstract}

\section{RESUMO}

Objetivo: O presente artigo objetivou identificar o estado vacinal dos adolescentes da área adscrita de uma Unidade Básica de Saúde da Família de uma cidade no Estado do Piauí. Métodos: Trata-se de um estudo seccional com abordagem quantitativa, desenvolvido por meio de inquérito domiciliar, no período de abril a julho de 2017. A amostra foi constituída por 361 adolescentes e a análise foi realizada por meio de estatística descritiva. Resultados: Verificou-se que, a cobertura vacinal contra rubéola, sarampo e caxumba atingiu $42,7 \%$ dos adolescentes, difteria e tétano $(31,9 \%)$, hepatite-B observou-se $42,1 \%$ de cobertura, enquanto que, $43,2 \%$ dos adolescentes foram vacinados contra febre amarela e $21,1 \%$ contra HPV. Destaca-se que, aproximadamente $50 \%$ dos entrevistados desconhecem a existência de um cartão de vacina do adolescente e que $58,8 \%$ dos adolescentes não sabiam informar contra quais doenças estavam imunizados. Conclusão: Conclui-se que o conhecimento dos adolescentes é incipiente em relação à imunização, destacando-se assim, a necessidade da realização de ações educativas pelos profissionais da saúde em parceria com as escolas.

Palavras-chave: Cobertura vacinal, Imunização, Adolescente.

\begin{abstract}
Objective: The present article aimed to identify the vaccination status of adolescents from the attached area of a Basic Family Health Unit in a city in the State of Piauí. Methods: This is a sectional study with a quantitative approach, developed through a household survey, from April to July 2017. The sample consisted of 361 adolescents and the analysis was performed using descriptive statistics. Results: It was found that vaccination coverage against rubella, measles and mumps accounted for $42.7 \%$ of adolescents, diphtheria and tetanus (31.9\%), hepatitis-B, $42.1 \%$ coverage was observed, while $43.2 \%$ of the adolescents were vaccinated against yellow fever and $21.1 \%$ against HPV. It is noted that approximately $50 \%$ of the interviewees are unaware of the existence of a vaccine card of the adolescent and that $58.8 \%$ of the adolescents did not know to inform against which diseases they were immunized. Conclusion: It is concluded that the knowledge of the adolescents is incipient in relation to the immunization, highlighting, thus, the necessity of carrying out educative actions by the health professionals in partnership with the schools.
\end{abstract}

Keywords: Vaccination coverage, Immunization, Adolescente.

\footnotetext{
${ }^{1}$ Universidade Federal do Delta do Parnaíba (UFDPAR), Parnaíba-PI. *Email: at.tiago@hotmail.com

2 Universidade Estadual do Piauí (UESPI), Teresina-PI.

${ }^{3}$ Cristo Faculdade do Piauí (CHRISFAPI), Piripiri-PI.

4 Universidade Federal do Piauí (UFPI), Teresina-PI.
} 


\section{RESUMEN}

Objetivo: Este artículo tuvo como objetivo identificar el estado de vacunación de los adolescentes en el área inscrita en una Unidad Básica de Salud Familiar en una ciudad del estado de Piauí. Métodos: Este es un estudio seccional con un enfoque cuantitativo, desarrollado a través de una encuesta de hogares, de abril a julio de 2017. La muestra consistió en 361 adolescentes y el análisis se realizó utilizando estadísticas descriptivas. Resultados: Se encontró que la cobertura de vacunación contra la rubéola, el sarampión y las paperas alcanzó el $42.7 \%$ de los adolescentes, difteria y tétanos $(31,9 \%)$, hepatitis B, se observó una cobertura del $42,1 \%$, mientras que el $43.2 \%$ de los adolescentes fueron vacunados contra la fiebre amarilla y el $21.1 \%$ contra el VPH. Es de destacar que aproximadamente el $50 \%$ de los encuestados desconocen la existencia de una tarjeta de vacunación de un adolescente y que el $58,8 \%$ de los adolescentes no sabían informar contra qué enfermedades estaban inmunizados. Conclusión: Se concluye que el conocimiento de los adolescentes es incipiente en relación con la inmunización, destacando así la necesidad de acciones educativas por parte de profesionales de la salud en asociación con las escuelas.

Palabras clave: Cobertura de vacunación, Inmunización, Adolescente.

\section{INTRODUÇÃO}

A Organização Mundial de Saúde (OMS) define a adolescência como o momento da vida compreendido entre 10 e 19 anos. Considerada como um período marcado por intensas alterações relacionadas ao crescimento e desenvolvimento, quando ocorrem mudanças físicas, como o surgimento de características sexuais, e ainda, contempla a formação da personalidade e integração social (BRASIL, 2010).

É no período da adolescência que os indivíduos, dado a pouca experiência, ficam mais expostos às gravidezes indesejadas, são mais vulneráveis a determinados agravos - como violência, ao uso de drogas, Infecções Sexualmente Transmissíveis (IST's), acidentes, suicídios, e ainda, encontram-se mais expostos a doenças imunopreveníveis, como: Hepatite B, infecção pelo Papiloma Vírus Humano (HPV), tétano, dentre outros agravos (ARAÚJO TME, et al., 2010).

O Programa Nacional de Imunização (PNI) incluiu os adolescentes entre os grupos prioritários ao considerar a situação de vulnerabilidade dos mesmos às várias doenças imunopreveníveis. O objetivo desta tomada de decisão é a redução da morbimortalidade por agravos imunopreveníveis através da melhora da cobertura vacinal em campanhas nacionais e na rotina das unidades de saúde (JULIANO Y, et al., 2008).

Para os adolescentes o PNI adota as seguintes vacinas como componentes do calendário básico desta faixa etária: vacina contra Hepatite B (VHB), vacina contra febre amarela (em áreas consideradas endêmicas), vacina contra difteria e tétano (dupla adulta/dT), vacina contra papilomavírus humano (HPV), vacina contra sarampo e rubéola (dupla viral) ou contra sarampo, caxumba e rubéola (tríplice viral) (BRASIL, 2014).

De acordo com a atual política de saúde, a imunização é executada, preferencialmente, no âmbito da Atenção Primária a Saúde (APS), pelas equipes de Estratégia Saúde da Família (ESF) (CARVALHO AMC e ARAÚJO TME, 2010). A APS é campo propício à inclusão da saúde integral dos adolescentes, tendo como objetivos o acompanhamento do crescimento e desenvolvimento, a orientação nutricional, as imunizações, as ações educativas, a identificação e tratamento de agravos e doenças prevalentes (COSTA COM e BIGRAS $M, 2007)$.

Diante do exposto, e considerando a importância da cobertura vacinal, enquanto um indicador de saúde relevante, este estudo objetivou identificar o estado vacinal dos adolescentes residentes de um território adscrito, referente a uma Unidade Básica de Saúde (UBS) de um município do estado do Piauí.

\section{MÉTODOS}

Trata-se de um estudo descritivo e de abordagem quantitativa, realizado através de inquérito domiciliar em um município do estado do Piauí. A população fonte do estudo foi composta por 3.702 adolescentes cadastrados no Sistema de informação em saúde para a Atenção Básica (SISAB, 2014) em uma UBS da do 
município estudado. Para o cálculo amostral, por meio de amostra aleatória simples, levou-se em consideração um erro tolerável de 5\%, com nível de significância de 95\%, obtendo-se 361 participantes. Segundo a fórmula que segue (CALLEGARI-JACQUES SM, 2003): $n=\mathrm{N}$.no/N+no

Onde $\mathrm{n}=$ tamanho da amostra , $\mathrm{N}$ = tamanho da população, no = primeira aproximação ao tamanho da amostra (no $=1 / E 2), E=$ erro tolerável.

Para a seleção dos participantes, utilizou-se uma técnica probabilística na qual as unidades amostrais são grupos (clusters) de elementos, conhecida como amostragem por conglomerados 30 por 7 (FREITAS H, et al., 2000). Conglomerados são determinados por limites geográficos ou políticos. No primeiro momento se sorteiam 30 conglomerados de modo proporcional ao tamanho populacional. No segundo momento, são selecionados sete participantes da faixa etária estudada em cada conglomerado. $O$ primeiro domicílio deve ser sorteado, e, a partir deste, os participantes dos domicílios subsequentes são entrevistados (BARATA RB, et al., 2005). Em inquéritos de cobertura vacinal a Organização Mundial de Saúde recomenta tal técnica que possui uma precisão de 10\% e 95\% de confiança (HENDERSON RH e SUNDARESAN T, 1982).

O território da UBS pesquisada era composto por quatro áreas, vinte e duas microáreas, em um total de cento e quarenta e um quarteirões. Para este estudo, cada quarteirão foi considerado um conglomerado e recebeu uma numeração. No primeiro momento foram sorteados 52 conglomerados, 30 e em seguida mais 12 conglomerados totalizando 42 com a finalidade de atingir o cálculo da amostra. No segundo momento construiu-se os croquis das áreas (unidades amostrais), numerou-se as ruas e sorteou-se qual se daria 0 início da busca dos participantes da pesquisa. No terceiro momento, sorteou-se o lado da rua seguido também do domicilio utilizado como ponto de partida. Sorteou-se apenas o primeiro domicílio, usando este como ponto de partida para a busca dos adolescentes nos domicílios subseqüentes.

A próxima etapa foi concluir a busca de sete adolescentes por conglomerado considerando a presença dos pais para aqueles menores de idade para a a assinatura do Termo de Consentimento Livre e Esclarecido (TCLE) e do Termo de Assentimento Livre e Esclarecido (TALE). Considerou-se apenas um adolescente por domicílio respeitando o sorteio e quando o mesmo não se encontrava em domicílio, foram realizados até dois retornos.

Os dados foram coletados no período de abril a julho de 2017, por meio de entrevistas com os adolescentes, que responderam um questionário contendo perguntas abertas e fechadas, aplicado pelos próprios pesquisadores com auxílio de estudantes de enfermagem, previamente orientados sobre o estudo. Utilizou-se de um formulário pré-testado, no período de março de 2017, pelos pesquisadores auxiliados por uma equipe de estudantes.

As variáveis do estudo foram as que seguem: dados socioeconômicos e demográficos, informações relacionadas ao cartão vacinal, cobertura vacinal, posse do cartão e o conhecimento acerca dos tipos de vacinas e as doenças por elas protegidas. Os dados foram categorizados e posteriormente digitados e processados com a utilização do software Statistical Package for the Social Science® (SPSS), versão 19.0. A análise dos dados foi feita por meio de estatísticas descritivas simples, como frequência absoluta e percentuais.

O projeto de pesquisa foi aprovado pelo Comitê de Ética em Pesquisa da Universidade Estadual do Piauí (UESPI) (CAAE: 66641917.0.0000.5209). Aos participantes foi apresentado o TCLE e TALE, garantida a confidencialidade e a privacidade, a proteção da imagem, a não estigmatização e a não utilização de informações em prejuízo das pessoas, conforme os princípios norteadores dispostos na Resolução nํㄴ 466/12, do Conselho Nacional de Saúde (BRASIL, 2012).

\section{RESULTADOS E DISCUSSÃO}

Para caracterizar a população pesquisada quanto suas condições socioeconômicas, observam-se uma predominância de adolescentes na faixa etária de 10 a 13 anos (43,8\%), sendo 47,4\% do gênero masculino, contra $52,6 \%$ do gênero feminino. Eram ainda, 67,6\% de cor parda autorreferida, 99,2\% solteiros e 98,3\% não tinham filhos (Tabela 1). 
Destaca-se que, a maioria dos entrevistados (60,7\%) possuía ensino fundamental incompleto. Quanto a renda familiar, $56,2 \%$ informaram renda de até 1 salário mínimo, dado que apresentou contraste com pesquisa realizada em Teresina no ano de 2008, que mostrou que $61 \%$ dos entrevistados possuíam renda familiar de dois a três salários mínimos (Tabela 1) (ARAÚJO TME, et al., 2010).

Destaca-se ainda, que a maioria dos entrevistados não possuía renda própria (93,1\% ), 93,4\% não trabalhavam fora de casa e $88,9 \%$ dos adolescentes moravam com os pais (Tabela 1 ).

Tabela 1 - Caracterização socioeconômica dos adolescentes, n=361. Teresina-PI, 2017.

\begin{tabular}{|c|c|c|}
\hline Variáveis socioeconômicas & $\mathbf{N}$ & $\%$ \\
\hline \multicolumn{3}{|l|}{ Faixa etária } \\
\hline 10 a 13 anos & 158 & 43,8 \\
\hline 14 a 16 anos & 126 & 34,9 \\
\hline 17 a 19 anos & 77 & 21,3 \\
\hline \multicolumn{3}{|l|}{ Gênero } \\
\hline Feminino & 190 & 52,6 \\
\hline Masculino & 171 & 47,4 \\
\hline \multicolumn{3}{|l|}{ Cor } \\
\hline Branco & 58 & 16,1 \\
\hline Negro & 59 & 16,3 \\
\hline Pardo & 244 & 67,6 \\
\hline \multicolumn{3}{|l|}{ Estado civil } \\
\hline Solteiro & 358 & 99,2 \\
\hline União estável & 3 & 0,8 \\
\hline \multicolumn{3}{|l|}{ Possui filhos } \\
\hline Sim & 6 & 1,7 \\
\hline Não & 355 & 98,3 \\
\hline \multicolumn{3}{|l|}{ Escolaridade } \\
\hline Ensino fundamental incompleto & 219 & 60,7 \\
\hline Ensino fundamental completo & 8 & 2,2 \\
\hline Ensino médio incompleto & 130 & 36,0 \\
\hline Ensino médio completo & 4 & 1,1 \\
\hline \multicolumn{3}{|l|}{ Renda familiar } \\
\hline Até 1 salário mínimo & 203 & 56,2 \\
\hline De 1 a 2 salários mínimos & 102 & 31,0 \\
\hline Acima de 2 salários mínimos & 46 & 12,7 \\
\hline \multicolumn{3}{|l|}{ Possui renda própria } \\
\hline Sim & 25 & 6,9 \\
\hline Não & 336 & 93,1 \\
\hline \multicolumn{3}{|l|}{ Trabalha fora de casa } \\
\hline Sim & 24 & 6,6 \\
\hline Não & 337 & 93,4 \\
\hline \multicolumn{3}{|l|}{ Com quem mora } \\
\hline Com os pais & 321 & 88,9 \\
\hline Companheiro & 2 & 0,6 \\
\hline Com os avos & 31 & 8,6 \\
\hline Outros & 7 & 1,9 \\
\hline Total & 361 & 100,0 \\
\hline
\end{tabular}

Fonte: Souza ATS, et al., 2020. 
Em relação à posse do cartão de vacinação, a Figura 1 mostra que 52,9\% dos adolescentes não possuíam cartão de vacina e entre os motivos elencados encontrou-se: perda do cartão $(97,9 \%)$, ter deixado em outra casa $(3,1 \%)$, e $46,8 \%$ dos entrevistados afirmaram não ter conhecimento do cartão ou calendário de vacinação do adolescente (Figura 2). Depreende-se do exposto que, o elevado percentual de adolescentes que afirmou desconhecer ou não possuir o cartão de vacina pode ser reflexo de lacunas ou falhas acerca dos cuidados dispensados a saúde dos adolescentes, bem como, da pouca exploração desse assunto no espaço das escolas daquela região, visto que os adolescentes são oriundos de áreas completamente cobertas pelas equipes ESF. É necessário, portanto, que as equipes multiprofissionais que atuam na área em estudo realizem atividades de educação em saúde para a comunidade, alertando os pais ou responsáveis e adolescentes quanto à importância da imunização e das doenças imunopreveníveis.

Figura 1 - Percentual de adolescentes que possuem ou não cartão de vacina, n=361. Teresina - PI, 2017.

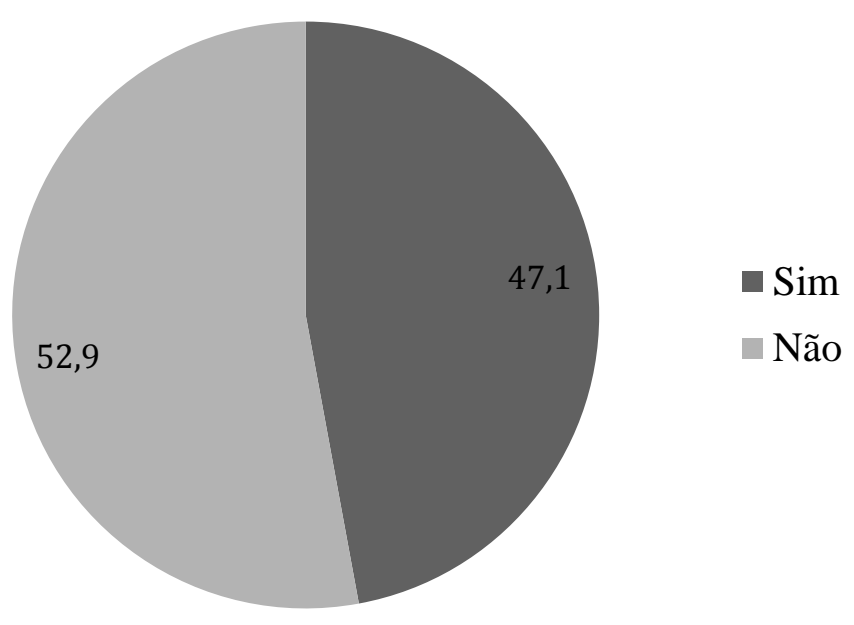

Fonte: Souza ATS, et al., 2020.

Figura 2 - Conhecimento dos adolescentes acerca do cartão de vacina do adolescente e das vacinas indicadas nessa faixa etária, $\mathrm{n}=361$. Teresina-PI, 2017.

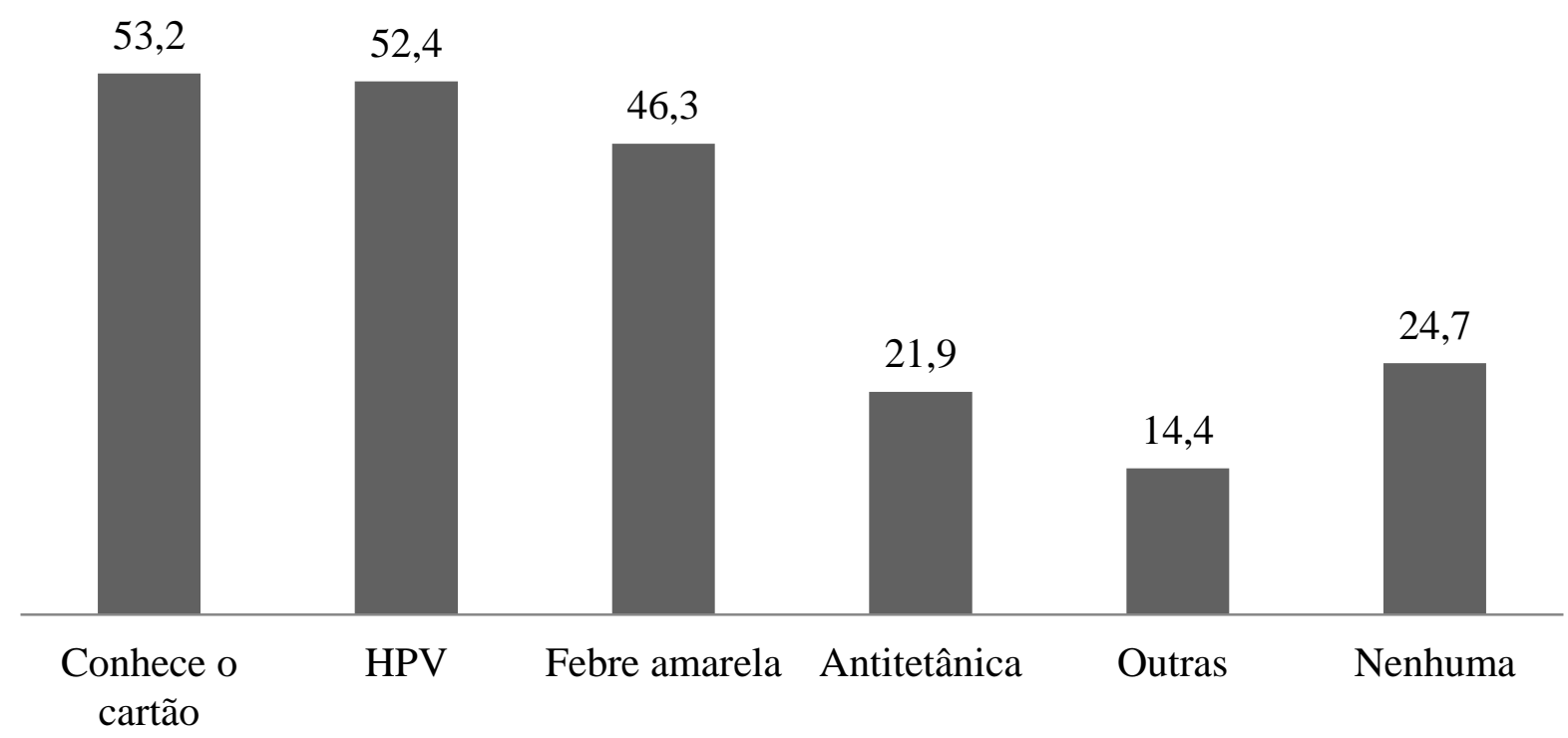

Fonte: Souza ATS, et al., 2020. 
Na presente pesquisa, a maioria $(53,2 \%)$ dos entrevistados afirmaram conhecer o cartão (Figura 2), contrapondo os achados de uma pesquisa realizada em Teresina, que definiu que $60,2 \%$ dos entrevistados desconheciam o cartão de vacina do adolescente (CARVALHO AMC e ARAÚJO TME, 2012). Quanto ao reconhecimento das vacinas, as que mais se destacaram foram a vacina contra o Papiloma Vírus Humano (HPV), citada por $52,4 \%$ dos adolescentes. Atribui-se esse fato, às intensas campanhas informativas sobre esta temática, as quais foram amplamente divulgadas nas mídias, desde o ano de 2014, período que o Ministério da Saúde, por meio do PNI, implantou a vacinação como estratégia de saúde pública no combate as doenças causadas pelo vírus HPV (Figura 2) (BRASIL, 2015). A segunda vacina mais citada foi a da febre amarela, por 46,3\% dos entrevistados, corroborando com o estudo de Carvalho AMC e Araújo TME (2012), no qual $48,6 \%$ dos adolescentes citaram esta vacina como mais lembrada. Sabe-se que esta vacina também tem encontrado amplo espaço de veiculação de informações, devido aos últimos surtos de febre amarela no país (Figura 2). De outro lado, a vacina menos conhecida foi a antitetânica, (78,1\%). Ainda, apenas 14,4\% dos adolescentes afirmaram conhecer outras vacinas além das destacadas.

Sobre a baixa cobertura vacinal no recorte geracional estudado, acredita-se que pode estar relacionado ao desconhecimento dos adolescentes em relação às vacinas, pois $24,7 \%$ dos adolescentes afirmaram não conhecer nenhuma vacina, e sobre as doenças que são transmissíveis e imunopreveníveis, ainda revelaram não saber responder ou serem leigos em relação ao cartão de vacinação do adolescente. $O$ ápice do desconhecimento de certos adolescentes revelou-se quando afirmaram conhecer vacinas que sequer foram desenvolvidas, a exemplo da vacina contra HIV (Figura 2).

Estudo realizado com 124 acadêmicos ingressantes em cursos da área de saúde em uma universidade pública mostrou resultados similares ao encontrado nesta pesquisa, onde apenas $39,5 \%$ dos mesmos estavam com calendário vacinal completo e $60,5 \%$ apresentavam esquema incompleto. Como possível causa da baixa cobertura vacinal em adolescentes é apontada pelos pesquisadores a ausência de campanhas públicas dirigidas para esta população (NARDELLI GC, et al., 2016).

Tabela 2 - Cobertura vacinal dos adolescentes quanto à imunização contra HPV, febre amarela, antitetânica, hepatite B, tríplice viral segundo o sexo, n=361. Teresina-PI, 2017.

\begin{tabular}{|c|c|c|c|}
\hline \multirow[b]{2}{*}{ Vacinas } & \multicolumn{2}{|c|}{ Sexo } & \multirow[b]{2}{*}{$\begin{array}{l}\text { Total } \\
\mathrm{n}(\%)\end{array}$} \\
\hline & $\begin{array}{c}\text { Feminino } \\
n(\%)\end{array}$ & $\begin{array}{c}\text { Masculino } \\
\mathrm{n}(\%)\end{array}$ & \\
\hline \multicolumn{4}{|l|}{ Tríplice viral } \\
\hline Vacinação completa & $89(46,8)$ & $65(38,0)$ & $154(42,7)$ \\
\hline Vacinação incompleta & $3(1,6)$ & $2(1,2)$ & $5(1,4)$ \\
\hline Não vacinado & $98(51,6)$ & $104(60,8)$ & $202(56,0)$ \\
\hline \multicolumn{4}{|l|}{ Hepatite B } \\
\hline Vacinação completa & $92(48,4)$ & $60(35,1)$ & $152(42,1)$ \\
\hline Vacinação incompleta & $3(1,6)$ & $8(4,7)$ & $11(3,0)$ \\
\hline Não vacinado & $95(50,0)$ & $103(60,2)$ & $198(54,8)$ \\
\hline \multicolumn{4}{|l|}{ Febre Amarela } \\
\hline Vacinação completa & $91(47,9)$ & $65(38,0)$ & $156(43,2)$ \\
\hline Não vacinado & $99(52,1)$ & $106(62,0)$ & $205(56,8)$ \\
\hline \multicolumn{4}{|l|}{ Antitetânica } \\
\hline Vacinação completa & $70(36,8)$ & $45(26,3)$ & $115(31,9)$ \\
\hline Vacinação incompleta & $16(8,4)$ & $15(8,8)$ & $31(8,6)$ \\
\hline Não vacinado & $104(54,7)$ & $111(64,9)$ & $215(59,6)$ \\
\hline \multicolumn{4}{|l|}{ HPV } \\
\hline Vacinação completa & $65(34,2)$ & $11(6,4)$ & $76(21,1)$ \\
\hline Vacinação incompleta & $14(7,4)$ & $28(16,4)$ & $42(11,6)$ \\
\hline Não vacinado & $111(58,4)$ & $132(77,2)$ & $243(67,3)$ \\
\hline Total & $190(100,0)$ & $171(100,0)$ & $361(100,0)$ \\
\hline
\end{tabular}

Fonte: Souza ATS, et al., 2020. 
Observa-se que a vacina que apresenta maior cobertura é a febre amarela $(43,2 \%)$, enquanto que, a com menor cobertura referida foi a do HPV $(21,1 \%)$, mesmo tendo sido reconhecida como a mais lembrada pelos adolescentes (Tabela 2). Essa baixa cobertura identificada preocupa, pois segundo dados preliminares de um estudo de metanálise, do Ministério da Saúde, que avaliou a prevalência nacional do HPV, constatou-se que os jovens entre 16 e 25 anos do município desta pesquisa, apresentaram prevalência de 54, $3 \%$ de casos de HPV, sendo que 34, 6\% com presença de HPV de alto risco (POP - BRASIL, 2017). A melhor forma de evitar a infecção pelo HPV ainda é a prevenção, podendo ser realizada pelo uso de preservativos, e pela vacinação, que faz parte do PNI desde 2014 (BRASIL, 2013).

Com a maior cobertura vacinal apontada no estudo para a vacina da febre amarela, uma possível explicação é o fato da mesma ser ofertada à população há mais de 60 anos e pela modificação do esquema vacinal proposto pelo MS em 2017, sendo necessário apenas uma dose na vida em substituição à necessidade de uma dose a cada 10 anos. Estudos apontam evidências de 99\% de imunidade protetora ocorrendo 30 dias após a vacinação com dose única (CAVALCANTE KRLJ e TAUIL PL, 2016, BRASIL, 2017).

Acerca da vacinação contra sarampo, caxumba e rubéola, apenas $42,7 \%$ dos entrevistados havia recebido a vacina. Resultado muito abaixo do esperado tal qual estudo realizado no Piauí com estudantes de enfermagem de uma universidade privada na qual 33,3\% do alunos investigados apresentaram esquema vacinal completo da vacina Tríplice Viral. (MARQUES ADB, et al., 2009).

Confirmando o incipiente conhecimento dos adolescentes a respeito da importância da prevenção contra a Hepatite $B$, e ainda, quanto aos seus modos de transmissão, observou-se que ela também apresentou baixa cobertura vacinal, $(42,1 \%)$. Outros estudos realizados com adolescentes no estado do Paraná (PUDELC P, et al., 2014) e do Piauí (CARVALHO AMC e ARAÚJO TME, 2010) também identificaram baixas coberturas vacinais contra a hepatite $B$. Achados divergentes foram em pesquisa realizada na China (BÖDEKER $B$, et al., 2015), com menores de 20 anos que possuíam a taxa de imunização contra o vírus da Hepatite B de $93,3 \%$.

A vacina da Hepatite B vem sendo ofertada pelo PNI desde 1989 para alguns grupos prioritários e regiões brasileiras. Em 1996 a vacina foi disponibilizada para menores de 2 anos de idade e após isto houve inclusão gradativa dos jovens e adultos. Somente em 2016 a VHB foi estendida para a população em geral independente da idade ou fatores de risco. A orientação para jovens e adultos é de esquema vacinal constituído de três doses, porém é necessário exame sorológico anti-HBs para certeza de imunização uma vez que receber as três doses não significa estar imune (ARRELIAS CCA, et al., 2016).

Considera-se ser necessária maior atenção em relação à baixa cobertura vacinal da Hepatite $B$ nos adolescentes, tendo em vista que a hepatite é caracterizada como um importante problema de saúde pública devido ao número de indivíduos acometidos e das complicações advindas das formas agudas e crônicas da infecção (PASSOS AM, et al., 2011).

Entre as adolescentes observa-se a maior cobertura para a vacina contra febre amarela, em $47,9 \%$ das meninas e a menor para HPV, em $34,2 \%$ delas (Tabela 2). Adverte-se que, a cobertura vacinal para HPV não alcançou nem a média nacional relativa ao ano de 2015 que foi de 44,25\%, segundo o estudo de Machado PA e Alcântara ACM (2016). Dessa forma, estando bem distante da meta preconizada pelo Ministério da Saúde que é de imunizar $80 \%$ das adolescentes compreendidas entre 9 a 13 anos.

Para o sexo masculino as maiores coberturas foram para as vacinas tríplice viral e febre amarela (ambas com percentual de 38,0\%) e a menor cobertura para HPV (com percentual de 6,4\%) (Tabela 2). Acredita-se que essa baixa cobertura para HPV em meninos deva-se ao fato de que no ano de 2017 o Ministério da Saúde preconizou e disponibilizou as vacinas para os meninos entre 12 e 13 anos. Espera-se que essa cobertura vacinal aumente, visto que esta faixa etária será ampliada até 2020 quando serão incluídos os de 9 a 13 anos, contudo, deve-se estar atento às estratégias de mídia que serão postas em prática (BRASIL, 2016).

Observaram-se em relação à cobertura vacinal dos adolescentes desse estudo, que as coberturas vacinais encontram-se abaixo do recomendado para todas as vacinas, quando comparadas com dados de pesquisas realizadas em Teresina no ano de 2008 (CARVALHO AMC e ARAÚJO TME, 2010). 
Os achados desse estudo revelaram a necessidade de realização de atividades de educação em saúde por parte dos profissionais que atuam na APS. Na atenção à saúde dispensada a população, no que tange a prática do cuidado integral, os adolescentes são colocados muitas vezes a margem dos cuidados, o que resulta em um não reconhecimento da UBS como um lugar seguro para cuidar da saúde dos mesmos. Acrescenta-se ainda que sentimentos de rebeldia e independência inerente a esta idade, também são fatores que afastam estes adolescentes de práticas preventivas e de promoção da saúde.

Figura 3 - Conhecimento dos adolescentes acerca da proteção das vacinas aplicadas conforme dados do cartão de vacina, $\mathrm{n}=170$. Teresina-PI, 2017.

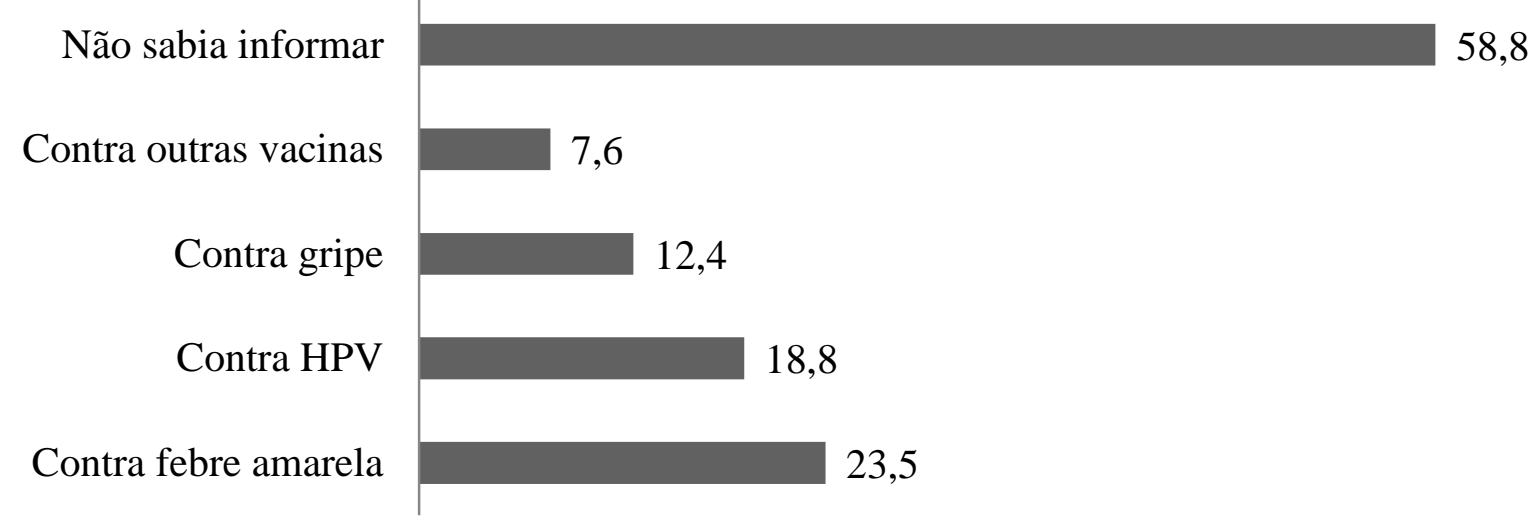

Fonte: Souza ATS, et al., 2020.

Ao perguntar quais doenças eram prevenidas pelas vacinas que os adolescentes já receberam as doses, os participantes, na sua maioria, fizeram referência à gripe, febre amarela e HPV. Visto que essas doenças e agente etiológico possuem nomes semelhantes aos das suas respectivas vacinas. Também vale ressaltar, que uma parcela muito expressiva, $58,8 \%$ dos adolescentes apresentaram cartão de vacina, mesmo não sabendo informar contra quais doenças estariam imunizados (Figura 3). $O$ fato revelou que mais da metade dos adolescentes que receberam imunização possuíam deficiência de conhecimento acerca das vacinas recomendadas pelo calendário do Ministério da Saúde e das doenças que estavam sendo imunizados ou adquirindo proteção.

Surpreende-se ao encontrar uma população pouco esclarecida quanto ao calendário de vacinação, visto que a imunização é ação prioritária das equipes de ESF, inclusive em faixas etárias peculiares, como a adolescência. Essa deficiência do conhecimento dos adolescentes leva a uma reflexão sobre a importância da educação em saúde feita de forma correta, onde se consideram os adolescentes como sujeitos ativos e responsáveis pela sua saúde.

Carvalho AMC e Araújo TME (2012) defendem ser a escola um ambiente propício para que se desenvolva um programa de educação em saúde, visto ser um local onde o adolescente adquire informações e conhecimentos necessários à sua vida social e pessoal, bem como estabelece relações interpessoais, que influenciarão no seu comportamento e no modo como se relaciona.

Na mesma lógica, um estudo de revisão sistemática da literatura discutiu sobre fatores que influenciavam a conclusão dos calendários vacinais multidoses em adolescentes e apontou que a administração da vacina nas escolas está associada a uma maior completude do calendário vacinal dos adolescentes, uma vez que a minoria dessa população procura unidades de saúde (GALLAGHER KE, et al., 2016).

Por fim, considera-se que a articulação entre educação e saúde, corrobora com as ideias de Paulo Freire, que considera educação como sendo ferramenta primordial para o estabelecimento de diálogo, e não apenas transferência de informação, podendo promover um momento de reflexão crítica, autonomia e de incentivo a adoção de uma postura que contribua no cuidado a saúde (FERNANDES MCP e BACKES VMS, 2010). 
De acordo com Carvalho AMC e Araújo TME (2012), o Programa Saúde na Escola (PSE) é ferramenta imprescindível para manter os adolescentes conscientes sobre os benefícios da vacinação. Considera-se que o PSE proporciona uma excelente oportunidade para manter os adolescentes informados sobre as vacinas recomendadas no calendário de vacinação, e consequentemente melhorar a cobertura vacinal.

\section{CONSIDERAÇÕES FINAIS}

Destaca-se a necessidade de ações educativas realizadas por profissionais de saúde da UBS na qual o estudo foi realizado visando esclarecer e informar aos adolescentes em relação à imunização. Para tanto, sugere-se a criação de parcerias significativas entre os profissionais da ESF e as escolas da comunidade, através da busca dos adolescentes e fornecimento das vacinas em ambiente escolar, objetivando produzir novas dimensões do cuidado. Destaca-se que o presente estudo contribuiu para a identificação dos adolescentes que necessitavam de atualização vacinal, pois todos os adolescentes que possuíam esquema vacinal incompleto ou aqueles sem cartão de vacina foram encaminhados para a sala de vacina da UBS da área pesquisada, para atualização de sua respectiva caderneta de vacinação.

\section{REFERÊNCIAS}

1. ARAÚJO TME, et al. Cobertura vacinal e fatores relacionados à vacinação dos adolescentes residentes na área norte de Teresina/PI. Rev. Eletr. Enf. 2010, 12(3): 502-10. DOI: http://dx.doi.org/ 10.5216/ree.v12i3.6934.

2. ARRELIAS CCA, et al. Cobertura vacinal contra hepatite $B$ em pacientes com diabetes mellitus. Rev esc enferm USP. 2016, 50(2): 255-62. DOI: https://doi.org/10.1590/S0080-623420160000200011.

3. BARATA RB, et al. Inquérito de cobertura vacinal: avaliação empírica da técnica de amostragem por conglomerados proposta pela Organização Mundial da Saúde. Rev. Panam. Salud. Publica. 2005, 17(3):184-90.

4. BÖDEKER, B, et al. Why are older adults and individuals with underlying chronic diseases in Germany not vaccinated against flu? A population-based study. BMC Public Health. 2015, 7(15): 1-10. DOI: http://dx.doi.org/10.1186/s12889015-1970-4

5. BRASIL, Câmara dos Deputados. Estatuto da Criança e do Adolescente (1990). 7ª Edição. Brasília. Edições Câmara, 2010. 225p. Série legislação. n.25

6. BRASIL, Conselho Nacional de Saúde. Diretrizes e normas regulamentadoras de pesquisas envolvendo seres humanos: Resolução n. 466/2012. Brasília, 2012.

7. BRASIL, Ministério da Saúde. Controle dos cânceres do colo do útero e de mama. Caderno de atenção básica. no 13, Brasília, 2013.

8. BRASIL, Ministério da Saúde. Secretaria de Vigilância em Saúde. Departamento de Vigilância das Doenças Transmissíveis. Manual de Procedimentos para Vacinação. Brasília: Ministério da Saúde, 2014.

9. BRASIL, Ministério da Saúde. Secretaria de Vigilância em Saúde. Departamento de Vigilância de Doenças Transmissíveis. Coordenação-Geral do Programa Nacional de Imunizações. Informe Técnico da Vacina Papilomavírus Humano 6,11, 16 E 18 (Recombinante). Adaptado pelo Programa Estadual de Imunizações/Rs, Brasília, 2015.

10. BRASIL, Ministério da Saúde. Secretaria de Vigilância em Saúde. Departamento de Vigilância de Doenças Transmissíveis. Coordenação-Geral do Programa Nacional de Imunizações. Informe Técnico Referente às Mudanças no Calendário Nacional de Vacinação para o Ano de 2017. Brasília, 2016.

11. BRASIL, Ministério da Saúde. Secretaria de Vigilância em Saúde. Departamento de Vigilância das Doenças Transmissíveis. COES - febre amarela. Nota informativa no 94. Brasília, 2017.

12. CALLEGARI-JACQUES, SM. Bioestatística: princípios e aplicações. 1.ed. Porto Alegre: Artmed, 2003, 255p.

13. CARVALHO AMC, ARAÚJO TME. Fatores associados à cobertura vacinal em adolescentes. Acta Paul. Enferm. 2010, 23(6): 796-802. DOI: http://dx.doi.org/10.1590/S0103-21002010000600013.

14. CARVALHO AMC, ARAÚJO TME. Conhecimento do adolescente sobre vacina no ambiente da Estratégia Saúde da Família. Rev Bras Enferm. 2012, 65(2): 229-235. DOI: http://dx.doi.org/10.1590/S0034-71672012000200005.

15. CAVALCANTE KRLJ, TAUIL PL. Características epidemiológicas da febre amarela no Brasil 2000-2012. Epidemiol serv saude. 2016, 25(1): 11- 20. DOI: https://doi.org/10.5123/S1679- 49742016000100002.

16. COSTA COM, BIGRAS M. Mecanismos pessoais e coletivos de proteção e promoção da qualidade de vida para a infância e adolescência. Ciênc. Saúde Coletiva. 2007, 12(5): 1101-1109. DOI: http://dx.doi.org/10.1590/S141381232007000500002.

17. FERNANDES MCP, BACKES VMS. Educação em saúde: perspectivas de uma equipe da Estratégia Saúde da Família sob a óptica de Paulo Freire. Rev Bras Enferm. 2010, 63(4): 567-73. DOI: http://dx.doi.org/10.1590/S003471672010000400011.

18. FREITAS H, et al. O método de pesquisa survey. Revista de Administração. 2000, 35(3):105-112.

19. GALLAGHER KE et al. Factors influencing completion of multi-dose vaccine schedules in adolescents: a systematic review. BMC Public Health, 2016, 16(1): 1-17. DOI: https://doi.org/10.1186/s12889-016-2845-z 
20. HENDERSON RH, SUNDARESAN T. Cluster sampling to assess immunization coverage: a review of experience with a simplified sampling method. Bull World Health Organ. 1982, 60(2): 253-60.

21. JULIANO Y, et al. Segunda etapa da Campanha Nacional de Multivacinação do município de São Paulo, 2005: perfil de cobertura de diferentes Unidades Básicas de Saúde. Rev. paul. pediatr. 2008, 26(1): 14-19. DOI: http://dx.doi.org/10.1590/S0103-05822008000100003.

22. MACHADO PAT, ALCÂNTARA ACM. Cobertura Vacinal contra o HPV em Meninas de 09 a 11 Anos no Município de Rolim de Moura - RO. Rev. Enfermagem e Saúde Coletiva. 2016, 1(2): 74 - 90.

23. MARQUES ADB, et al. Cobertura vacinal dos acadêmicos de enfermagem de uma faculdade privada do Piauí. Revista interdisciplinar. 2013, 6(2): 75-83.

24. NARDELLI GG, et al. Situação vacinal de ingressantes da área da saúde de uma universidade pública. Revista família ciclos de vida e saúde no contexto social. 2016, 4(2):145-61. DOI: http://dx.doi.org/10.18554/refacs.v4i2.1645.

25. PASSOS AM, et al. Hepatitis B immunity and vaccination coverage among young adult males in the Air Force in South Brazil. Vaccine. 2011, 29(49): 9284-9288. DOI: http://dx.doi.org/10.1016/j.vaccine.2011.06.050.

26. POP-BRASIL. Estudo Epidemiológico sobre a Prevalência Nacional de Infecção pelo HPV (POP-Brasil): Resultados preliminares [Internet]. 2017.

27. PUDELCO P, et al. Impacto da vacinação na redução da hepatite B no Paraná. Rev Gaúcha Enferm. 2014, 35(1): 78-86. DOI: http://dx.doi.org/10.1590/1983-1447.2014.01.37821

28. Sistema de Informação em Saúde para a Atenção Básica (SISAB). Fundação Municipal de Saúde de Teresina (PI). Relatório de Cadastro das Equipes e Cadastros de Família. Teresina (PI), 2014. 